\title{
Impact of changes in land use and climate on the Runoff in the coastal areas of South China-A case study of the Nanliujiang catchment
}

\author{
Mingzhi Yang ${ }^{1}$, Weihua Xiao ${ }^{1, a}$, Yong Zhao ${ }^{1}$, Ya Huang ${ }^{2}$, Baoqi Li ${ }^{1}$, Dachuan Jiang ${ }^{1}$, Fan Lu ${ }^{1}$ and Baodeng Hou ${ }^{1}$ \\ ${ }^{1}$ State Key Laboratory of Simulation and Regulation of Water Cycle in River Basin, China Institute of Water Resources and Hydropower \\ Research, Beijing 100038, China \\ ${ }^{2}$ College of Civil Engineering and Architecture, Guangxi University, Nanning, Guangxi 530004, China
}

\begin{abstract}
The intense climate changes and human activities have a great impact on the variation of the runoff of the coastal area of South China. In this work, the Soil and Water Assessment Tool (SWAT) is used to quantify the impact of land use and climate change of the Nanliujiang catchment on the runoff by setting 4 scenarios of land-use and climate change. The results show the runoff of the simulated and measured values had a similar trend. The value of relevant coefficient is above 0.8 , and the value of NashSutcliffe efficiency coefficient is about 0.8 , which indicate that the SWAT model is fit for the study area. The annual average runoff depth during the period from 1995 to 2013 has increased by $53.5 \mathrm{~mm}$, of which the land use change resulted in $13.0 \mathrm{~mm}$ increase on the annual average runoff depth while the climate change resulted in $40.9 \mathrm{~mm}$ increase on the annual average runoff depth, therefore, the climate change has greater effect then the land use change. This work will delineate some helpful information for the water resources management as well as ecological protection in the coastal area of South China.
\end{abstract}

\section{Introduction}

The IPCC Fifth Assessment Report (AR5) on climate change points out that, in the last half a century, almost all parts of the world have gone through the global warming process [1], and region with the fastest growing temperature is the mid - northern latitudes [2]. Under the climate change, the intense human activity has a large impact on hydrology and water resources, of which the change of land use and land cover is one of the most important factors affecting water resources. It has been conducted much study on that subject in home and abroad [3-6].

At present, there have been many researches on the air temperature and precipitation variation characteristics under climate changes in different regions, the results vary and each has its own particularities. Most of the researches are on the Yellow river basin [7], the Yangtze river basin [8-10], the Northwest [11-13] and the North China and so on, however, but few studies on the regulation of the humid and rainy regions in South China [14], especially the quantitative research of the impacts of changes in land use and climate on hydrology in South China. The Nanliujiang catchment is the important region of modernized cities and industrial groups in the coastal area of South China. In recent years, the rapid economic development, industrialization and urbanization of the basin has caused great change on land use. Climate change, population growth, rapid economic development, and the intense production activities have made water resource become the bottleneck for social and economic development in the region. Therefore the quantitative analysis of the impacts of land use and climate change has significance on the flood control and drought relief, water resources management and planning of the Nanliujiang catchment.

Based on the "future climate change scenariohydrological simulation-effect analysis", as well as the current climate change research results, the two factors that affect the water resource the most, i.e. temperature and precipitation are selected, and the SWAT model is used to simulate the hydrological process of the Nanliujiang catchment. By setting the climate change scenario, the work made quantitative analysis on the influence of the two factors on the Nanliujiang catchment runoff, and analyze the influence of a single land use type and the impacts of different climate changes on runoff in order to provides important scientific evidence on water resources planning and management under the climate changes and human activities.

\section{Study area}

The Nanliujiang catchment is located in the south of Guangxi province (Figure 1), lies between longitudes $109^{\circ} 00^{\prime} 03^{\prime}$ to $110^{\circ} 23^{\prime} 12^{\prime \prime} \mathrm{E}$ and latitudes $21^{\circ} 35^{\prime} 5^{\prime}$ 'to $22^{\circ} 52^{\prime} 32^{\prime \prime} \mathrm{N}$, borders the Darong Mountain on the North, the North Bay on the South. It is northeast high - lying,

a Corresponding author: xiaoweihua@iwhr.com 
southwest of the low, with a drop of more than $1250 \mathrm{~m}$. It belongs to subtropics monsoon climate region, with an average annual air temperature $21.5 \sim 23.1^{\circ} \mathrm{Cwinter}$ is mild with less rainfall, and summer humid and hot with abundant rainfall. Average annual precipitation is $1600 \sim 1800 \mathrm{~mm}$. The water resource is mainly supplied by precipitation in the study area, the average water resource amount is 7.53 billion $\mathrm{m}^{3}$. However, the spatial and temporal distribution of water resources is uneven with large inter-annual changes. The rain season lasts from May to September and accounts for $60 \%$ to $80 \%$ of the total annual amount, the maximum runoff usually occurs in July and August, the maximum and minimum monthly runoff rate $5 \sim 50$.

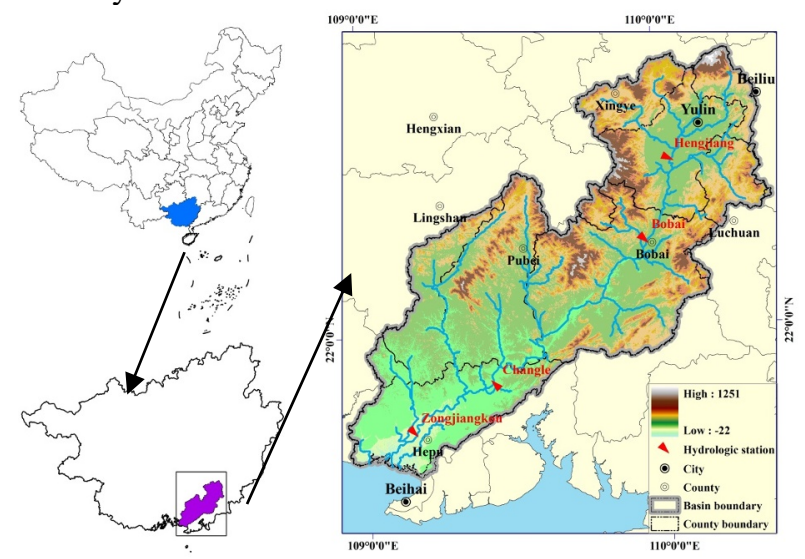

Figure 1. The location and topography of the study area

\section{Materials and methods}

\subsection{Materials}

The data required for SWAT model are as follows : a) Digital elevation model (DEM) data; b) the land use map of the Nanliujiang catchment in 1995 and 2014 is taken from the remote sensing data collected by the Chinese Academy of Sciences. The land use classification system of the SWAT model is based on the United States Geological Survey (USGS), therefore, based on the relevant research data, code conversion of land use is done within the river basin; c) Soil data for study area was provided by the China Soil Science Database (http://www.soil.csdb.cn/). The cubic spline interpolation method is used to convert soil particle into USGS standards. The SPAW is used to convert USGS standard soil parameters, and import it into the model database. d) the monthly runoff data of Zongjiangkou hydrometric stations from 1967 to 2013 . e) the meteorological data of five stations from 1957 to 2013, including average daily air temperature, daily maximum air temperature and minimum air temperature, the average relative humidity, daily precipitation, daily sunshine duration, average atmospheric pressure and wind speed.

According to the classification system of land resources in China [15], the land use types are divided into 6 categories, including forest land, farmland, grassland, water, construction land and unused land. In 1995, the land use in the study area (Fig.2a) are mainly the woodland $(59.33 \%)$, the arable land took the second
$(28.2 \%)$, unused land took the third $(7.12 \%)$, the construction land (3.01\%) and the grassland $(0.33 \%)$. In 2014 (Fig.2b), the woodland still took the dominance $(59.53 \%)$, mainly due to the expansion of dryland; the arable land was increased to $29.76 \%$, the unused land has decreased to $5.84 \%$, the construction land increased to $4.68 \%$, the grass is decreased to only $0.19 \%$.

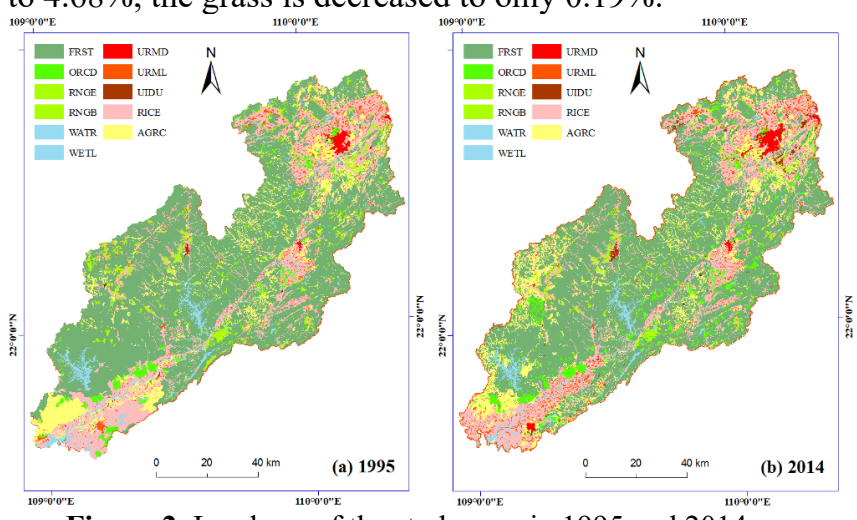

Figure 2. Land use of the study area in 1995 and 2014

\subsection{Methods}

\subsubsection{Mutation tests}

a. M-K test

Mann- Kendall method [16] is commonly used to predict long-term changes in hydrometeorological time series data such as temperature, precipitation, and runoff. [17-18], which is a non-parametric test method internationally widely used. Mann- Kendall test does not require the sample to follow a certain distribution, and is not interfered by a few abnormal values. The calculation is simple, and the detection range is wide. MK test method is as follows:

Construct the order column for the sample sequence $\mathrm{X}=\left(\mathrm{x}_{1}, \mathrm{x}_{2}, \ldots, \mathrm{x}_{\mathrm{n}}\right)$ :

$$
\begin{aligned}
& S_{k}=\sum_{i=1}^{k} r\left(x_{i}\right) \\
& r\left(x_{i}\right)=\left\{\begin{array}{ll}
1, & x_{i}>x_{j} \\
0, & x_{i} \leq x_{j}
\end{array}, j=1,2, \ldots, i\right.
\end{aligned}
$$

Where $r\left(x_{i}\right)$ represents the order of observations.

Amount of statistics

$$
\begin{gathered}
U F_{k}=\frac{S_{k}-E\left(S_{k}\right)}{\sqrt{\operatorname{Var}\left(S_{k}\right)}}, k=1,2, \ldots, n \\
E\left(S_{k}\right)=\frac{n(n+1)}{4} \\
\operatorname{Var}\left(S_{k}\right)=\frac{n(n-1)(2 n+5)}{72}
\end{gathered}
$$

In this formula, $E\left(S_{k}\right)$ and $\operatorname{Var}\left(S_{k}\right)$ represents the mean and variance of the cumulative number $S_{k}$.

For a given significant level $\alpha$, if $U F_{k}>\left|U F_{1-\alpha / 2}\right|$, it indicates that there is a significant trend in the sequence.

The time series are arranged in the reverse order of X, and are calculated according to the equations (1)-(5), while making $U B_{k}=-U F_{k}, k=n, n-1, \ldots, 1$. The $U F_{k}$ and $U B_{k}$ statistics are plotted as a curve. If $U F_{k}>0$ or $U B_{k}>$ 
0 , the sequence is in an upward trend, otherwise the sequence is in a downward trend. When they exceed the critical line range and determine the region where the mutation occurs, if the intersection of the two curves appears and the intersection is within the critical line, then the time corresponding to the intersection is the time at which the mutation begins.

b. T-test

If multiple mutation points are obtained by the Mann-Kendall rank correlation test, the mutation points are accurately identified by the sliding $\mathrm{T}$ test to determine whether significant mutations have occurred. Methods are as below:

With the known sequence $x_{t}(\mathrm{t}=1,2, \ldots, \mathrm{n})$, the statistic $T$ values were calculated by taking consecutive $n_{1}$ and $n_{2}$ data sequences adjacent to each other before and after the mutation point.

$$
\begin{gathered}
T=\frac{\overline{x_{1}}-\overline{x_{2}}}{S \sqrt{\frac{1}{n_{1}}+\frac{1}{n_{2}}}} \\
S=\sqrt{\frac{\left(n_{1}-1\right) S_{1}^{2}+\left(n_{2}-1\right) S_{2}^{2}}{n_{1}+n_{2}-2}}
\end{gathered}
$$

In this formula $, \overline{x_{1}}, \overline{x_{2}}, \mathrm{~s}_{1}$ and $\mathrm{s}_{2}$ represent the mean and standard deviation of consecutive $n_{1}$ and $n_{2}$ years, respectively.

Calculate the statistic $\mathrm{T}$, given the significance level $\alpha=0.05$, and the degree of freedom is $\mathrm{n}=\mathrm{n}_{1}+\mathrm{n}_{2}-2$ and the $\mathrm{T}_{\alpha / 2}$ value is obtained by the $t$ distribution table. When $|\mathrm{T}|>\mathrm{T}_{\alpha / 2}$, indicating that the sequence has significant variation at this point, then the point is the point of mutation. The meteorological sequence data is divided into two segments, $\mathrm{T}_{1}$ and $\mathrm{T}_{2}$, which are the data series before and after the mutation.

\subsubsection{Parameters calibration}

In this work, calibration efforts focused on improving model performance at main gauging station (Zongjiangkou station) in study area. In order to reduce the error, it sets 1967-1969 as the warm-up period, T2 as the correction period and $\mathrm{T} 1$ as the qualification period. The distributed hydrological model has a lot of parameters, finding the sensitive parameters are of great significance for calibration. SUFI-2 algorithm [19-20] is used to conduct repeatedly calculation to determine the best value for the parameter; the correlation coefficient $\left(R^{2}\right)$ and Nash-Sutcliffe efficiency factor $\left(E_{n s}\right)$ are selected to evaluate the applicability of the SWAT model in the Nanliujiang catchment. The relevant studies show that when $R^{2}>0.6, E_{n s}>0.5$, the simulation will get the best effect.

The correlation coefficient $\mathrm{R}^{2}$ shows how identical is the simulated and the measured value. When $R^{2}=1$, it indicates that the simulated value is totally identical with the measured value, reflecting the relevance of the simulated and measured values. The closer the value to 1 , the better the correlation between the two is; the smaller the value, the worse the correlation of the two is. The calculation formula is as follow:
$R^{2}=\frac{\left(\sum_{i=1}^{n}\left(Q_{s i m, i}-\overline{Q_{s i m}}\right)\left(Q_{o b s, i}-\overline{Q_{o b s}}\right)\right)^{2}}{\sum_{i=1}^{n}\left(Q_{s i m, i}-\overline{Q_{s i m}}\right)^{2} \sum_{i=1}^{n}\left(Q_{o b s, i}-\overline{Q_{o b s}}\right)^{2}}$

Where $\overline{Q_{\text {sim }}}$ is the average runoff; $\overline{Q_{o b s}}$ is the measured average runoff; $\mathrm{n}$ is the number of observations.

The Nash efficiency coefficient (Nash-Suttcliffe) indicates that the fitting of the measured value and the simulated value, allowing values vary from 0 to 1 . When the value is close to 1 , it means a better simulation result; when the value is less than 0 , it means the credibility of the model simulation value is less than the measured average value. The calculation formula is as follow:

$$
E_{n s}=1-\frac{\sum_{i=1}^{n}\left(Q_{o b s, i}-Q_{s i m, i}\right)^{2}}{\sum_{i=1}^{n}\left(Q_{o b s, i}-\overline{Q_{o b s}}\right)^{2}}
$$

\subsubsection{Scenarios}

According to the results of the two mutation tests, the comprehensive scenario of land-use and climate change (Table 1): the two periods (T1 and T2) are used for assessment of climate change impact on hydrological processes; the land use data in 1995 and 2014 are used for assessment of land use change impact on hydrological processes. The study uses the SWAT model to simulate four scenarios: land-use in 1995 and climate data in T1 (S1), land-use in 2014 and climate data in T1 (S2), land-use in 1995 and climate data in T2 (S3), landuse in 2014 and climate data in T2 (S4). S1 and S4 are used to describe the comprehensive impact of land use and clime change in the two periods. The comparison of $\mathrm{S} 2$ and $\mathrm{S} 1$ is used to describe the impact of land use change on hydrological process; the comparison of S3 and $\mathrm{S} 1$ is used to describe the climate changes on hydrological process.

Table 1. Integrated scenarios for modeling analysis

\begin{tabular}{|c|c|c|}
\hline \multirow{2}{*}{ Scenario } & \multicolumn{2}{|c|}{ data series } \\
\cline { 2 - 3 } & Land use data & Meteorological data \\
\hline S1 & 1995 & T1 \\
\hline S2 & 2014 & T1 \\
\hline S3 & 1995 & T2 \\
\hline S4 & 2014 & T2 \\
\hline
\end{tabular}

\section{Results and Discussion}

\subsection{Mutation analyses}

The MK test was used to analyze the precipitation sequence of the Nanliujiang catchment. The results are shown in Figure 3a. Before 1992, UF $>0$, the precipitation showed no significant growth trend; after 1992, $\mathrm{UF}<0$, indicating that the precipitation is fluctuating. The downward trend and the downward trend are not obvious. Over time, UF and UB intersect at multiple points in the upper and lower critical values of 
0.05 dominant levels. The intersections are in 1988, 1994 and 1996, respectively. It can be seen that MannKendall test is used to find multiple mutation points and it is difficult to determine whether significant mutations have occurred. It is necessary to continue the T test, as shown in Figure $3 \mathrm{~b}$. As can be seen from the figure, the $\mathrm{T}$ value exceeded the significant level in 1994, and it was judged that 1994 was a significant mutation point.

Combined with MK test and $\mathrm{T}$ test, the precipitation time series was analyzed to determine that the rainfall in the Nanliujiang catchment was abruptly changed in 1994, and the precipitation sequence data was divided into two sections: T1 (1970-1994) and T2 (1995- 2013).

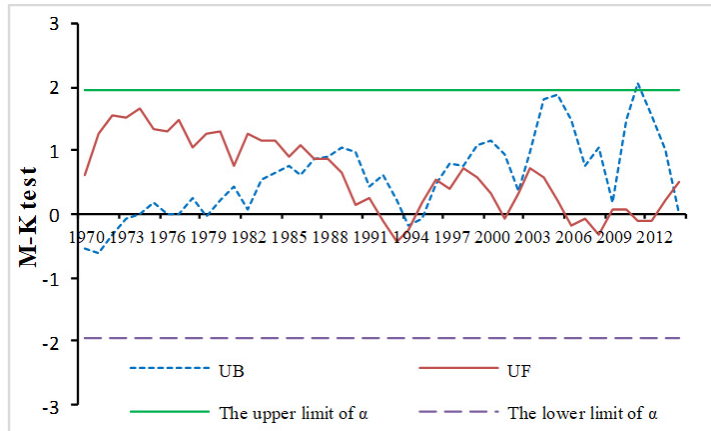

(a)

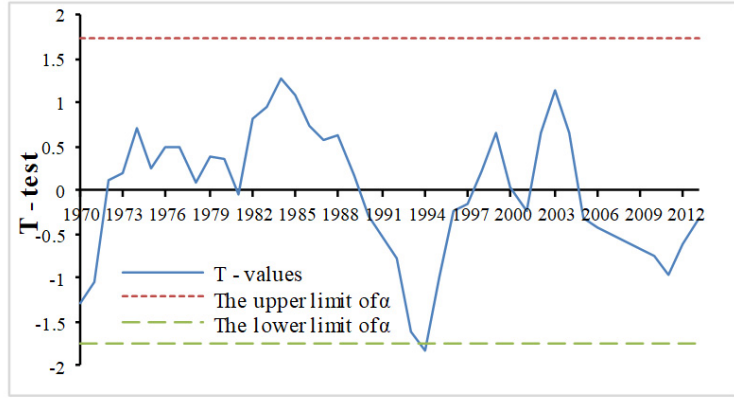

(b)

Figure 3. Precipitation $M-K$ test (a) and T-test (b)

\subsection{Model validation}

Calibration and validation are achieved via the SUFI-2 algorithm. The results show that after the correction and validation, the accuracy of the simulated value of the monthly streamflow at the Nanliujiang catchment in the calibration and verification period has met the standard (Figure 4). In verification period, the deterministic coefficient $R^{2}$ is 0.84 , together with the values of $E_{n s}$ which is above 0.80 (Table 2). It can be seen that the simulation model has high accuracy, which means that the SWAT model is applicable to this catchment.

Table 2. Model performance regarding monthly streamflow at the Zongjiangkou station, for the calibration and validation periods. $\mathrm{R}^{2}$ — deterministic coefficient; $\mathrm{E}_{\mathrm{ns}}-\mathrm{Nash}$-Sutcliffe coefficient.

\begin{tabular}{|c|c|c|c|}
\hline \multicolumn{2}{|c|}{ Calibration(1970-1994) } & \multicolumn{2}{c|}{ Validation(1995-2013) } \\
\hline $\mathrm{R}^{2}$ & $\mathrm{E}_{\mathrm{ns}}$ & $\mathrm{R}^{2}$ & $\mathrm{E}_{\mathrm{ns}}$ \\
\hline 0.82 & 0.81 & 0.84 & 0.82 \\
\hline
\end{tabular}

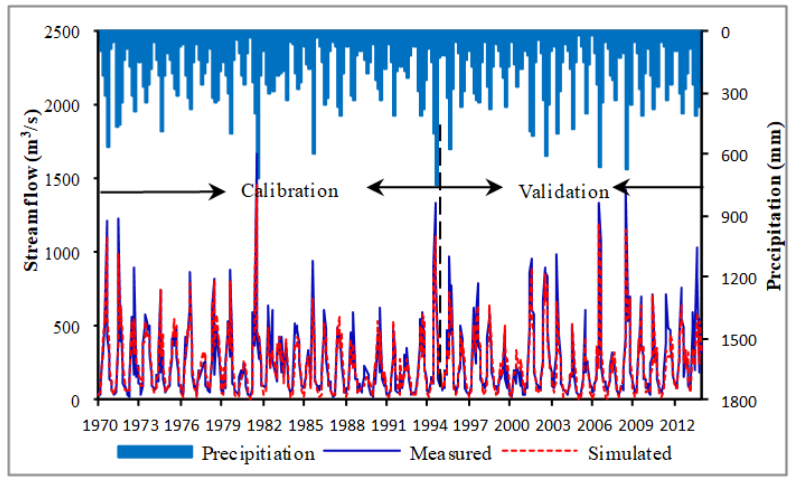

Figure 4. Comparison of the simulated and measured monthly stream discharge at Zongjiangkou station.

\subsection{Scenario analyses}

As it is shown in Table3, the average annual runoff of S1, $\mathrm{S} 2, \mathrm{~S} 3$ and S4, are 863.5, 876.5, 904.4, 917.0mm respectively. The comparison between $\mathrm{S} 4$ and $\mathrm{S} 1$ shows that the comprehensive effects of land use and climate change may lead to the average annual runoff to increase by $53.5 \mathrm{~mm}$. The comparison between $\mathrm{S} 2, \mathrm{~S} 1$ shows that the land use variation has caused the average annual runoff to increase by $13.0 \mathrm{~mm}$; however, the comparison of S3 and S1 shows that climate change may lead to the average annual runoff to increase by $40.9 \mathrm{~mm}$. Compared with $\mathrm{S} 1$, the average annual temperature of S3 increases $0.5^{\circ} \mathrm{C}(2.2 \%)$, with the average annual precipitation decreases by $30.3 \mathrm{~mm}(7.4 \%)$. Compared with S1, the construction land of S4 has increased but with little in amount; the woodland decreased as the farmland expands. It can be seen that climate change has a lager impact on runoff than land-use change. It is probably because the climate change can directly affect the hydrological cycling, the impact of land use change is indirect; the reduction of woodland may led to increase of runoff, which can be attributed to the water conservation function of woodland. In the context of climate change, people can optimize the land use types and the spatial distribution through a rational land-use planning, so as to reduce the impacts of flood and draught in the study area. It may offer a reference for water resource planning and management.

Table 3. Simulation results of integrated scenarios

\begin{tabular}{|c|c|c|c|c|c|}
\hline \multirow{2}{*}{ Scenario } & \multirow{2}{*}{$\begin{array}{c}\text { precipitation }(\mathrm{m} \\
\mathrm{m})\end{array}$} & $\begin{array}{c}\text { temperature } \\
\left({ }^{\circ} \mathrm{C}\right)\end{array}$ & \multirow{2}{*}{$\begin{array}{c}\text { runoff } \\
(\mathrm{mm})\end{array}$} & \multicolumn{2}{|c|}{ Effects on runoff } \\
\cline { 5 - 6 } & & & & land use & $\begin{array}{c}\text { climate } \\
\text { variability }\end{array}$ \\
\hline $\mathrm{S} 1$ & 1732.2 & 22.64 & 863.5 & - & - \\
\hline $\mathrm{S} 2$ & 1762.5 & 23.14 & 876.5 & +13.0 & - \\
\hline $\mathrm{S} 3$ & 1732.2 & 22.64 & 904.4 & - & +40.9 \\
\hline $\mathrm{S} 4$ & 1762.5 & 23.14 & 917.0 & +12.6 & +53.5 \\
\hline
\end{tabular}

\section{Conclusion}

The paper aims to analyze the impact of land use and climate change on runoff in the Nanliujiang basin based on the SWAT model with four scenarios. The results showed that: after the quantitative analysis of land use and climate change impact on runoff, it can be seen that, 
compared with the standard scenario 1, the average annual runoff caused by land use and climate change in scenario 4 increases by $53.5 \mathrm{~mm}$; the runoff caused by climate change increases by $40.9 \mathrm{~mm}$ in scenario 3 ; the runoff increases caused by the land use in scenario is $13.0 \mathrm{~mm}$. The climate change has a larger impact than land use. Therefore, We can address the hydrological effects, especially the negative effects, of the Nanliujiang catchment brought about by climate change by reasonable land use planning, land use structure and deployment optimization.

In this work, the impact of land use and climate change on runoff in the Nanliujiang catchment has been discussed. The work reduces the uncertainty through sensitivity analysis by selecting the sensitive parameters for debugging in the SWAT model setup. In addition, the land coverage and soil parameters in the SWAT model use the USGS standard which is quite different from our classification systems; therefore, the conversion may have some errors and uncertainties. The runoff depth caused by the land use change is comparatively small, the reason may be that the Nanliujiang catchment has a higher vegetation coverage, the land use change varies a lot but only with small coverage. This work only studies the issue from the perspective of annual runoff depth, in the next step, it can be studied from the annul wet and dry seasons. Under the comprehensive influence of climate change and human activities, the future underlying surface will definitely change and have impact on water resources, therefore in the next step, we may study the impact of climate and land use change on water resource which is the research focus.

\section{Acknowledgments}

This research is financially supported by the National Key Research and Development Program during the 13th Five-year Plan, Ministry of Science and Technology, PRC (2016YFA0601500) and the National Natural Science Foundation of China (No. 51679252).

Conflicts of Interest: The authors declare no conflict of interest.

\section{References}

1. T. Stocker, D.Qin, G. K. Plattner, The Physical Science Basis (2013)

2. F. Ji, Z.H.Wu, J.P.Huang, E.P.Chassignet. Evolution of land surface air temperature trend. Nature Climate Change, 4(2014)

3. H. Ma, D. Yang, S.K. Tanb, B. Gao, Q. Hua. Journal of Hydrology, 389(2010)

4. S. Ashraf Vaghefi, S.J. Mousavi, K. C. Abbaspour, R. Srinivasan. Hydrological Process, 28(2014)

5. F. Monireh, C. Karim, R. Schulin, H.Yang. Hydrological Processes, 23(2009)

6. S. Shrestha, A.Y. Htut. Environmental Modeling \& Assessment (2016)

7. D.F. Li, Y. Tian, C.M.Liu. Acta Geographica Sinica,
59 (2004)

8. Z.H. Xia, Y.H. Zhou, H.M. Xu. Resources and Environment in the Yangtze Basin, 19(2010)

9. X.J. Liang, H. Jiang, Q.A. Zhu, M.L. Huang. Research of Soil \& Water Conservation, 15 (2008)

10. Z. Deng, X. Zhang, D. Li, G. Pan. Environmental Earth Sciences, 73(2015)

11. S. Wang, S. Kang, L. Zhang, F. Li. Hydrological Processes, 22(2008)

12. L. Zhang, Z. Nan, W. Yu, Y.Ge. Water Resources Management, 29(2015)

13. J. Guo, X.L. Su, V.P. Singh, J. Jin. Water, 8(2016)

14. J. Yan, B. Chen, M. Feng, J.L. Innes. Advances in Meteorology.12(2013)

15. J.H. Zhang, Z.M. Feng. Resources Science, 33(2011)

16. B.M.H. Economet-rica, 13(1945)

17. B.G.V, H.J. P.Water Resources Research, 4(2001)

18. Z.Q, J.T, G.M. Hydrological Sciences Journal, 1(2005)

19. J. Schuol, K.C.Abbaspour, H.Yang, R.Srinivasan, A.J.B. Zehnder. Water Resources Research. 44(2008)

20. J. Zhou, Y. Liu, H. Guo, D. He. Hydrological Processes. 28(2014) 